\title{
USING FiSHER'S EXACT TEST IN THE ENGINEERING INDUSTRY
}

\author{
Katerina Bicova \&Martin Melichar
}
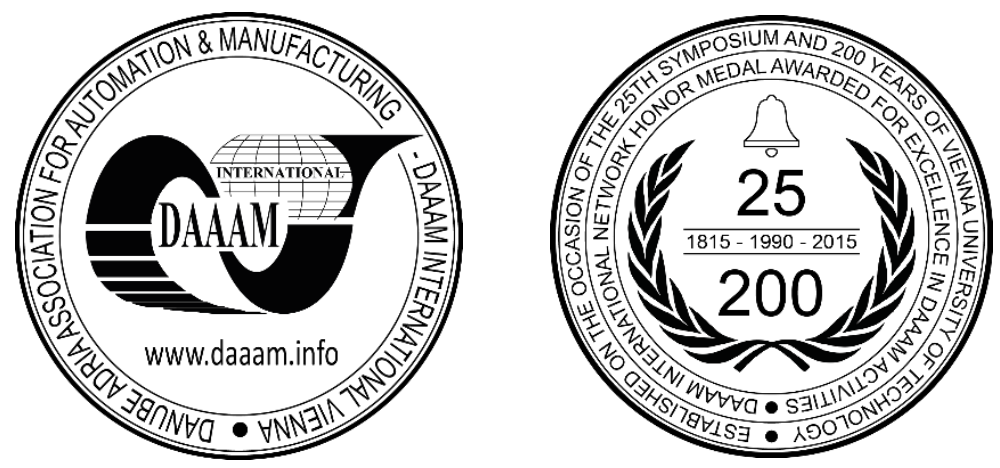

This Publication has to be referred as: Bicova, K[aterina] \& Melichar, M[artin] (2016). Using Fisher's Exact Test in the Engineering Industry, Proceedings of the 27th DAAAM International Symposium, pp.0349-0352, B. Katalinic (Ed.), Published by DAAAM International, ISBN 978-3-902734-08-2, ISSN 1726-9679, Vienna, Austria DOI: $10.2507 / 27$ th.daaam.proceedings.051

\begin{abstract}
This contribution solves the problem of monitoring precision manufacturing. Because, despite the high precision of production, there are fluctuations in precision during the day, the collected data is analyzed. The proposed analysis is to find out whether there is a dependence on the time of day precision. Next, using F-test to determine, whether the fluctuations in precision are significant. Another reason for this analysis are the requirements for continuous improvement, which is based on standard TS 16949 quality management system in the automotive field.
\end{abstract}

Keywords: Automotive industry; precise manufacturing; F-test; Statistical evaluation; Process.

\section{Introduction}

Automotive industry belongs to the most competitive branch of mechanical engineering. Companies fight for reach and prove their good names. Progressive technologies, product properties and services for customers are constantly developing.

This contribution describes an issue of precise production of machine parts evaluation and analysis. It works with data that came from serial production in automotive industry, where high precision and small amount of rejected parts play a big role. In our case, in spite of high precision of production, are there still significant fluctuations of precision during the day. From this reason, we did a detailed analysis of provided data form measurement in production line for giving suggestions, which should lead to production process improvement. The requirements for continual improvement of the process came from TS 16949 standard that works with quality management system in automotive industry. Top management shall review the product realization processes and the support processes to assure their effectiveness and efficiency. Statistical studies shall by conducted to analyse the variation present in the results of each type of measuring and test equipment system.[10]

\section{Problem description}

The subject of analysis is data from the output control produced machine parts. Controlled is a critical part dimensions. Measurement is carried out part of the innovative measuring technology Renishaw Equator (view Fig. 1). This innovative measuring system enables $100 \%$ control required because it is a very precise production of critical components in the automotive field. 
Why Renishaw Equator? When selecting, assessing and current possibilities of CMM on the market, any of them offer flexibility, used friendliness, performance measurement per unit of time. But only Equator has ability to work in automatic mode, for which the device is very well prepared. It devalues competitors in 3D measuring with the unique architecture, based on the parallel kinematics.

Automatic mode allows $100 \%$ control of the entire volume of parts of production. After comparison with the standard it can evaluate whether the measured piece is good or bad and display outputs on the control screen. The basic principle of the measurement process is based on comparing inspection = comparison measured part to the "golden" or etalon. "Golden" part is the one that is made as a model for mastering = initial setup of parameters before or during the measurement, temperature change, achieving limit number of checked items, or the expiry of the time limit, the setting, etc. [2].

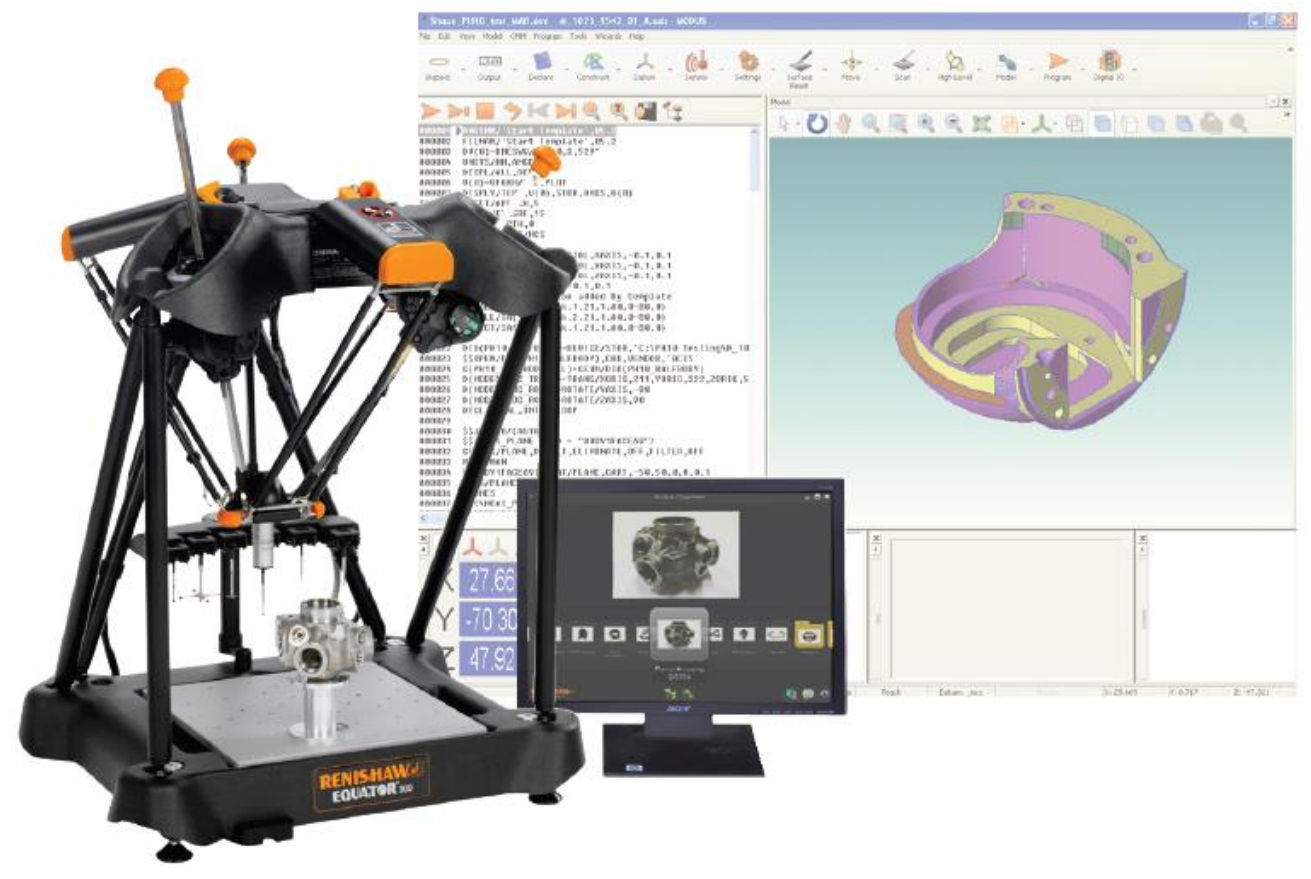

Fig. 1. Measuring device Equator[3]:

Production of components is carried out during the 24-hour standard (on the 3 shifts). People take turns regularly shifts. It is a stable process with high capability $1 \mathrm{ppm}$. Despite stable process fluctuations precision during the day.[1,9]

The proposed analysis is to find out whether there is a dependence on the time of day precision in production. Simultaneously, whether fluctuations in precision are significant. The measured data are accumulated over a period of one month. Of them is then formed an average curve precision during the day.

For analysis of the significance of fluctuations in precision was designed to compare the morning (6:00 to 14:00) and afternoon shifts (14:00 - 22:00). Is selected, 8am and 4pm. Based on the consideration that after coming to work one moment must be incorporated.

The performance value of each person's is variable, dependent on many factors. There are not only significant individual differences between people, but the performance also changes throughout life and even during the week and every working day.[8]

To compare the precision of production during the day could be contemplated Fisher test. This test is used to compare two measuring methods, devices or precision of production on two shifts. I.e. Testing the hypothesis that one shift is lower production precision than the second shift. Or for example, if we are testing a new process, we may only be interested in knowing if the new process is less variable than the old process. [7]

\section{Analysis of data - F-test}

U Statistical hypothesis testing belongs together with the methods of estimation theory to practice the most important statistical inference. To use parametric tests must be fulfilled the assumption of data normality of monitored variables. Between the parametric tests include primarily Student t-test for testing difference between the two mean values and F-test (Fisher test) for testing the difference of two variances.[4]

Assuming that during the measurement causes no systematic error, measurement precision is defined by the parameter $\sigma$. Therefore, when comparing two measurement methods A and B with a value $\sigma_{\mathrm{A}}$ and $\sigma_{\mathrm{B}}$, true that the smaller the value of $\sigma$ is more precise. If these are not known, they may be used to compare of the standard deviation. A random influences cause variation of standard deviations $s_{\mathrm{A}}$ and $\mathrm{s}_{\mathrm{B}}$ around the actual value $\sigma_{\mathrm{A}}$ and $\sigma_{\mathrm{B}}$. [5] 
Test criteria assuming hypothesis: $\mathrm{H} 0: \sigma_{\mathrm{A}}{ }^{2}=\sigma_{\mathrm{B}}{ }^{2}$ is equal to (Eq.1):

$F=\frac{s_{A}^{2} \cdot \frac{n_{1}}{n_{1}-1}}{s_{B}^{2} \cdot \frac{n_{2}}{n_{2}-1}}$

and simultaneously applies (Eq.2)

$F_{1-\alpha / 2}\left(f_{1}, f_{2}\right)=\frac{1}{F_{1-\alpha / 2}\left(f_{2}, f_{1}\right)}$

In this case, testing the hypothesis that one shift is lower production precision than the second shift. I.e. Test for independent series from two normal distributions, that on the morning shift (around 8 hours) is lower than the production precision on the afternoon shift (about 16 hours). Measured values are in following tab.1.

\begin{tabular}{|l|l|l|l|l|l|l|l|}
\hline \multicolumn{7}{|c|}{ Measured values during the morning and afternoon shifts } \\
\hline \multirow{4}{*}{$8 \mathrm{am}$} & 28.063 & 28.054 & 28.055 & 28.044 & 28.093 & 28.041 & 28.036 \\
\cline { 2 - 9 } & 28.031 & 28.055 & 28.051 & 28.036 & 28.055 & 28.083 & 28.066 \\
\cline { 2 - 8 } & 28.061 & 28.042 & 28.042 & 28.028 & 28.045 & 28.073 & 28.074 \\
\cline { 2 - 8 } & 28.047 & 28.053 & 28.049 & 28.065 & 28.048 & 28.051 & 28.049 \\
\hline \hline \multirow{4}{*}{$16 \mathrm{pm}$} & 28.038 & 28.048 & 28.047 & 28.035 & 28.034 & 28.028 & 28.028 \\
\cline { 2 - 8 } & 28.05 & 28.036 & 28.045 & 28.049 & 28.032 & 28.039 & 28.062 \\
\cline { 2 - 8 } & 28.036 & 28.054 & 28.03 & 28.043 & 28.064 & 28.048 & 28.059 \\
\cline { 2 - 8 } & 28.056 & 28.035 & 28.041 & 28.04 & 28.036 & 28.034 & 28.035 \\
\hline
\end{tabular}

Table 1. Measured values during the morning and afternoon shifts

\begin{tabular}{|l|l|l|}
\hline \multicolumn{3}{|c|}{ Fisher test of equality of variances } \\
\hline & morning & afternoon \\
\hline Variances & 0.000228 & 0.000103 \\
\hline Observation & 28 & 28 \\
\hline Reliability & $95 \%$ & \\
\hline F & $\mathbf{2 . 2 1 1 2}$ \\
\hline F crit & $\mathbf{1 . 9 0 4 8 2 3}$ \\
\hline Significance value p & $\mathbf{0 . 0 4 3 6 9}$ \\
\hline
\end{tabular}

Table 1. Hypothesis - Fisher test of equality of variance

According to tab.2 is critical field $\mathrm{W}_{0,05}: \mathrm{F} \geq \mathrm{F}_{\text {crit }}(27,27)$, tedy $\mathrm{F} \geq 1,904823$ [6]. The value of the test criteria $\mathrm{F}=2.2112$ falls into the critical field because the verdict $2.2112 \geq 1.904823$ applies, the hypothesis of equality of variances therefore the significance level of 0.05 in favor of rejecting the alternative hypothesis is representative of the fact that production is on the afternoon shift more precise than on the morning shift.

Result significance F-test: $\mathrm{p}=0.04369$ represents the probability of the null hypothesis of compliance variances of the two files (the probability of errors). Because this $\mathrm{p}<0.05$, it means that the difference between the variances is statistically significant. So the precision differs significantly.

More precise production on the afternoon shift is confirmed by the following chart, which shows the variation of precision during the day (Fig.2). 


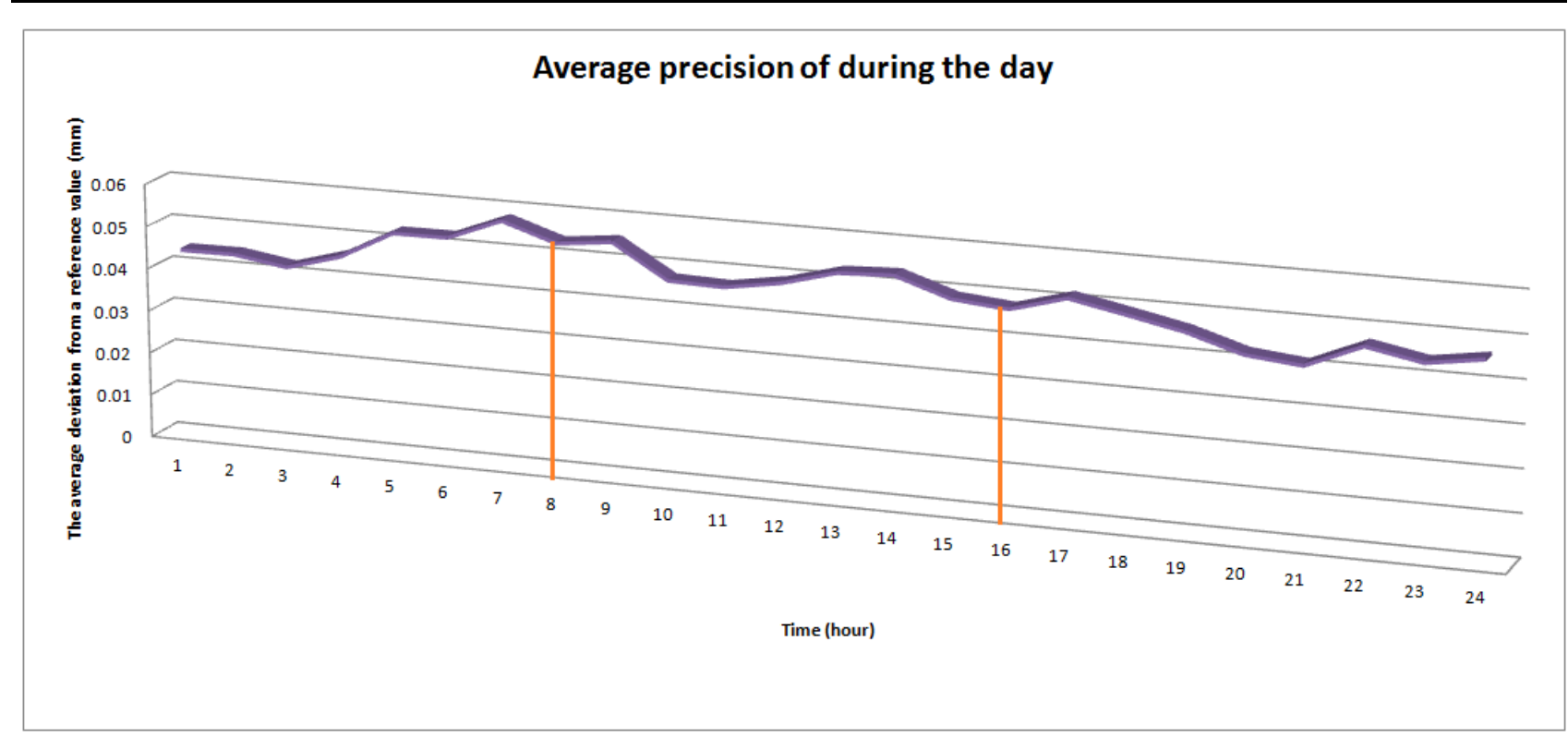

Fig. 2. Views average of manufacturing precision

\section{Conclusion}

Automotive sector has very strict production accuracy requirement. In business environment the time is important value. Automotive manufacturers are under customer pressure to a keep maximum of $5 \mathrm{ppm}$, which is very difficult to achieve and maintain.

The aim of the analysis was to determine whether there is a dependence on the daytime of manufacturing process and precision. Dependence on the time of day manufacturing precision is evident from the assembled curve average accuracy during the day (see Fig.2).

The analysis further shows that differences in accuracy between morning and afternoon shifts are significant. It would be appropriate to apply an additional tool for monitoring the process in order to identify the causes of these fluctuations. It is necessary to think that the key to any manufacturing or control process is the man with all his physiological aspects.

The organization shall continually improve the effectiveness of the quality management system through the use of quality objectives, audit results, analysis of data and management review.

\section{Acknowledgments}

This paper includes results created within the project SGS-2016-005.

\section{References}

[1] MSA (Measurement System Analysis) Praha : ČSJ, 2011. ISBN: 978-80-02-02323-5

[2] Martin Melichar, Dana Kubátová: Processing Data from Automatic Measurement Device, Procedia Engineering, Volume 100, 2015, Pages 899-906

[3] www.renishaw.cz/cs/equator-univerzalni-merici-system--13465.[online].[Cited: 20.8.2016]

[4] Lectures - Safety and Quality. [Online] [Cited: 12. 08 2016.]

http://cit.vfu.cz/statpotr/POTR/Teorie/Predn3/Ftest.htm.

[5] Kožǐšek, J., Stieberová, B. Statistic in example. Praha : Verlag Dashöfer, 2012. ISBN: 978-80-86897-48-6.

[6] Tabs - critical value [Online] [Cited: 9.5 2016.] http://www.kmt.zcu.cz/person/Kohout/info_soubory/letnisem/tabulky.htm

[7] Engineering Statistics Handbook. [Online] [Cited: 29. 07 2016.] http://www.itl.nist.gov/div898/handbook/eda/section3/eda359.htm

[8] Bicova, K.; Melichar, M.:Influence on the Shift the Product Precision of Machining Process and Eligibility, Proceedings of the 26th DAAAM International Symposium, pp.0508-0512, ISBN 978-3-902734-07-5, ISSN 1726-9679, Vienna, Austria

[9] Liviu Dorin Pop, Nagy Elod: Improving Product Quality by Implementing ISO / TS 16949, Procedia Technology, Volume 19, 2015, Pages 1004-1011

[10] CSN ISO/TS 16949:2009, Quality management system for automotive industry 